\title{
25 Research Square \\ SESR-based Identification of Flash Drought and Multivariate Drought Risk Probability Assessment in the Pearl River Basin, China
}

Bei Chen

Jinan University

Chuanhao Wu ( $\square$ wuch0907@jnu.edu.cn )

Jinan University

Pat J.-F. Yeh

Jinan University

Jiayun Li

Jinan University

Wenhan LV

Jinan University

Jin Zhao

Jinan University

\section{Research Article}

Keywords: flash drought, SESR, Copula, joint return period, Pearl River basin

Posted Date: November 1st, 2021

DOI: https://doi.org/10.21203/rs.3.rs-946601/v1

License: () (1) This work is licensed under a Creative Commons Attribution 4.0 International License.

Read Full License 


\section{SESR-based identification of flash drought and multivariate}

2 drought risk probability assessment in the Pearl River basin,

\section{China}

4 Bei Chen ${ }^{\mathrm{a}}$, Chuanhao $\mathrm{Wu}^{\mathrm{a} *}$, Pat J.-F. Yeh ${ }^{\mathrm{b}}$, Jiayun $\mathrm{Li}^{\mathrm{a}}$, Wenhan $\mathrm{Lv}^{\mathrm{c}}$, Jin

${ }^{a}$ Department of Ecology and Hydrobiology, Jinan University, Guangzhou 510632, China.

${ }^{\mathrm{b}}$ Discipline of Civil Engineering, School of Engineering, Monash University, Malaysia Campus,

9 Malaysia.

$10{ }^{\mathrm{c}}$ School of Water Resources and Environment, China University of Geosciences, Beijing, 100083,

11 China.

$12{ }^{\mathrm{d}}$ Haihe River, Huaihe River and Xiaoqinghe River Basin Water Conservancy Management and 13 Service Center of Shandong Province, Jinan, 250014, China.

14

15

16

17
1
Author for correspondence Chuanhao Wu (wuch0907@jnu.edu.cn) Department of Ecology and Hydrobiology, Jinan University, Guangzhou 510632, China. 
28 Abstract

Flash drought (FD) is characterized by the rapid onset and development of drought conditions. It usually occurs during the growing seasons, causing more severe impacts on agriculture and society than the slowly-evolving droughts. Based on the Standard Evaporative Stress Ratio (SESR), this study presents an assessment of the spatiotemporal variability of the joint return periods of FD characteristics in the Pearl River basin (PRB), southern China. Three FD characteristics (i.e., duration $D$, intensity $I$, peak $P$ ) are extracted at each $0.25^{\circ} \times 0.25^{\circ}$ grid point over the PRB by the Runs theory. Four marginal distribution functions (Gamma, Exponential, Generalized Extreme Value and Lognormal) are used to fit FD characteristics, while three Archimedean Copula functions (Clayton, Frank and Gumbel) are used for generating the joint distributions of various paired FD characteristics. The results indicate that Lognormal is the best-fitted marginal distribution function of FD characteristics in most parts of PRB, while Frank and Clayton are the best-fitted Copula of the joint PDFs of three pairs of FD characteristics in most parts of PRB. During 1953-2013, the FD events are more frequent in eastern PRB ( $>40$ events) than western PRB ( $<10$ events), and larger FD characteristics ( $D$ and $I$ ) are also found in eastern PRB than western PRB. The return period of each FD characteristic is smaller in eastern PRB than western PRB, leading to smaller joint return periods of three paired FD characteristics $(D-I, D-$ $P, P-I)$ in eastern PRB than western PRB. Overall, our results suggest that the risk of 
48 FD is gradually increased from the west to the east of the PRB.

49

\section{Key words:}

51 flash drought; SESR; Copula; joint return period; Pearl River basin 52

53

54 


\section{Introduction}

Drought refers to the phenomenon that water availability is in a prolonged deficit lasting for months or years (Ma et al. 2013; Mishra and Singh 2010; Xu et al. 2015). It is a recurrent, inevitable and devastating natural disaster causing significant loss to agriculture, ecology, and social economy (Allen et al. 2010). Global warming increases atmospheric evapotranspiration (ET) demand and leads to uneven distribution of precipitation, triggering frequent drought events in many regions of the world in recent years (Allan et al. 2008; Rahmstorf and Coumou 2011; TomasBurguera 2020; Vicente-Serrano 2016). Moreover, drought is expected to become more frequent and more intensity with greater negative impacts under the background of uncertain water supplies, increasing water demand and rapid population growth (Fontaine and Steinemann 2009; Qu et al. 2018; Xia and Wei 2016; Yan et al. 2016; Yin et al. 2015; Trenberth et al. 2014).

Recently, a new type of rapidly developing drought, flash drought (FD), has been receiving increasing attention from the scientific community. The onset and development of FD usually occur rapidly when extreme atmospheric anomalies (e.g., rainfall deficit and high surface temperature) persist for several days or weeks (Christian et al. 2019; Otkin et al. 2018). FD is most likely to occur in regions with dense vegetation during the growing seasons (Otkin et al. 2018; Wang et al. 2016). As FD is distinguished by its unusually rapid intensification, there is no early warning for FD, potentially causing more severe impacts on agriculture and society than the 

slowly-evolving droughts ( Ford et al. 2015; Otkin et al. 2018). Several alternative definitions of FD have been developed in recent years, and they generally can be classified into two types: one is based on the duration $(D)$ (Mo and Lettenmaier 2015, 2016), and the other is based on the rapid intensification rate (Ford 2017; Liu et al. 2020; Otkin et al. 2018). In addition, a variety of indices have also been developed to identify the occurrence of FD, including the rapid change index (RCI, Otkin et al. 2015), the Evaporative Stress Index (ESI) (Otkin et al. 2014), the Standard Evaporative Stress Ratio (SESR) (Christian et al. 2019), and the Standardized Evapotranspiration Deficit Index (SEDI) (Li et al. 2020). These metrics are based on the assumption that vegetation pressure is the key driving force of the occurrence of FD, therefore they are more suitable for the densely vegetation regions (Osman et al. 2021). More recently, Christian et al. (2019) developed an objective percentile-based methodology for identifying FD by using the SESR, which is a standardized form of the ratio between ET and potential evapotranspiration (PET). The SESR-based method not only considers the vegetative impacts of FD, but also reflects the dynamic changes and the rapid intensification of FD. In this study, the SESR-based method will be used to identify the occurrence of FD.

\section{Drought characteristics are considered essential elements of water resources and} drought management. Drought condition can be commonly characterized by multidimensional drought characteristics, such as $D$, intensity $(I)$, peak $(P)$ and frequency (Dracup et al. 1980). Single drought characteristic variable cannot fully reflect the authenticity of drought events, since different drought characteristics are 
interdependent (Ayantobo et al. 2018; Shiau 2006, 2009; Sharma and Goyal 2020). Therefore, different drought characteristics as well as their correlation structures and mutual impacts need to be examined together for providing accurate drought assessment (Nabaei et al. 2019; Wu et al. 2021). Most multivariate distributions are currently derived from univariate distributions, which require the same edge distributions of the variables, making the assessment less accurate (Salvadori and Michele 2004). By contrast, the copula method directly simulates the multivariate distribution of multiple random variables, providing a theoretical framework for the multivariate frequency analysis of various variables (Sklar 1959). In the past decade, the copula method has widely used in the multivariate frequency analysis of drought characteristics (Jha et al. 2019, 2020; Lee et al. 2013; Xu et al. 2015; Wu et al. 2021; Zhang et al. 2013), precipitation, runoff and flood (Wee and Shitan 2013; Renard and Lang 2007), and other hydro-meteorological variables like soil moisture, temperature, and sea level (Das and Maity 2015; Rana et al. 2017; Zhang et al. 2007). With this in mind, this study will apply the copula method to present basin-scale analysis of the joint return periods of the paired FD characteristics.

The Pearl River basin (PRB) is the largest basin in southern China, characterized by developed economy and agriculture, dense cities, large population, and farming areas. The climate of PRB is dominated by humid subtropical climate, mainly influenced by the East Asian monsoon (Zhang et al. 2019). Under global warming, the PRB is vulnerable to severe drought since the 1970s (Fischer et al. 2012; Zhang et al. 2013), including more frequent FDs in PRB in recent years (Wang et al. 2016; Wang and 
121 advances have been recently devoted to the analysis of FD in PRB (Wang and Yuan,

122 2021; Zhang et al. 2019), most of them are only based on the soil moisture decline

123 method, which cannot fully reflect the dynamic changes and the rapid intensification

124 of FD. In addition, to the best of our knowledge, the risk assessment of FD has not

125 yet been conducted in PRB. A systematic spatio-temporal risk assessment of FD

126 events would promote our understanding of the evolution of FD and provide new

127 insights for the implementation of FD forecasting and early warning systems in PRB.

128 Based on the SESR-based method developed by Christian et al. (2019), this study

129 aims to quantitatively evaluate the spatio-temporal variability of the joint return

130 period of FD characteristics in PRB by using the copula-based models. Particularly,

131 three FD characteristics (i.e., $D, I$ and $P$ ) computed based on the SESR are extracted

132 at each $0.25^{\circ} \times 0.25^{\circ}$ grid point over the PRB. Four marginal distribution functions

133 (Gamma, Exponential, Generalized Extreme Value and Lognormal) are used to fit $D, I$

134 and $P$, while three Archimedean Copula functions (Clayton, Frank and Gumbel) are

135 used for generating the joint distributions of various paired FD characteristics. The

136 best-fitted marginal distribution for each drought characteristic and the goodness

137 fitting copula functions are selected based on the root-mean-square error (RMSE) and

138 the Kolmogorov-Smirnov (K-S) test (Kolmogorov 1933; Smirnov 1948). In the

139 following, section 2 introduces the study area. In section 3, the detailed introductions

140 of dataset, definition of FD and drought characteristics, and analysis methods (Mann-

141 Kendall trend test, marginal distribution functions and Copula functions) are 

main findings drawn from this study are summarized in section 6 .

\section{Study area} River basin (WRB), the North River basin (NRB), the East River basin (ERB) and the

147 Pearl River Delta (PRD), with a total drainage area of $4.42 \times 10^{5} \mathrm{~km}^{2}$ (Fig. 1). The

148 PRB has a concentrated population and developed industry and agriculture, with a

149 high meteorological disaster vulnerability (Liu et al. 2012). The basin is dominated by

150 the tropical and subtropical monsoon climate, with annual mean temperature ranging

151 from 14 to $22{ }^{\circ} \mathrm{C}$, and annual mean precipitation decreasing from $2200 \mathrm{~mm}$ in the east

152 to $1200 \mathrm{~mm}$ in the west. The precipitation of PRB has an uneven intra-annual

153 distribution, with $60-70 \%$ of annual precipitation occurring during April-September

154 (Tang et al. 2015). Due to global warming, PRB is vulnerable to drought and short-

155 term concurrent hot and dry extreme events in recent years (Zhang et al. 2019).

\section{Dataset and Methodology}

\subsection{Dataset}

158 Atmospheric reanalysis makes a perfect combination of observations and earth system

159 models, and provides spatiotemporal estimates about the earth's atmosphere and land

160 surface variables (Koster 2019). Global Land Data Assimilation System (GLDAS)

161 aims to utilize advanced land surface modeling and data assimilation techniques to

162 obtain reliable estimates of land surface states and fluxes (Ji et al. 2015; Park and 
163

Choi 2015; Rodell et al. 2004). The high-quality, global land surface fields provided by the GLDAS have been widely used in weather and climate prediction, water resources applications, and water cycle investigations (Bi et al. 2016; Yuan et al. 2018). In this study, the long-term (1953-2013) daily ET data over the PRB with a spatial resolution of $0.25^{\circ}$ were driven from the GLDAS-2.0 forcing data (https://ldas.gsfc.nasa.gov/).

Observed daily meteorological data, including precipitation, mean temperature, maximum and minimum temperature, air pressure, vapor pressure, sunshine duration, and wind speed, spanning the period 1953-2013 were driven from 65 meteorological stations over the PRB (see Fig. 1) provided by the National Meteorological Information Center (http://data.cma.cn). Based on the meteorological observation data, daily PET was calculated by using the FAO-56 Penman-Monteith method (Mahrt and Michael 1984; Penman 1948). To match the spatial scale of GLDAS-2.0 data, the PET data was interpolated to $0.25^{\circ}$ spatial resolution over the PRB by using the bilinear interpolation.

\subsection{FD identification}

Christian et al. (2019) developed an objective percentile-based methodology for identifying the occurrence of FD using the SESR and changes in SESR. This method not only considers the vegetative impacts of FD, but also quantifies the rapid rate of drought intensification. Specifically, the FD identification is based on the evaporative stress ratio (ESR), which can be expressed as follows: 


$$
\mathrm{ESR}=\frac{\mathrm{ET}}{\mathrm{PET}}
$$

185 where ESR ranges from 0 to approximately 1 . The value of ESR is inversely

186 proportional to the amount of evaporative stress on the environment (Christian et al.

187 2019).

188 For the FD identification, the standardized ESR (i.e., SESR) and the standardized

189 change in SESR are computed at each grid point:

$$
\begin{gathered}
\operatorname{SESR}_{i j p}=\frac{\mathrm{ESR}_{i j p}-\overline{\mathrm{ESR}_{i j p}}}{\sigma_{\mathrm{ESR}_{i j p}}} \\
\left(\Delta \mathrm{SESR}_{i j p}\right)_{z}=\frac{\Delta \mathrm{SESR}_{i j p}-\overline{\Delta \mathrm{SESR}_{i j p}}}{\sigma_{\Delta S \mathrm{ESR}_{i j p}}}
\end{gathered}
$$

192 where $\mathrm{SESR}_{i j p}$ and $\left(\Delta \mathrm{SESR}_{i j p}\right)_{z}$ represent the z-score of ESR and change in SESR,

193 respectively, for a specific pentad $(p)$ at a specific grid point $(i, j)$. $\Delta$ SESR represents

194 the rapid intensification of FD in time at each grid point.

195 Taking into account the frequent characteristics of high-temperature heat waves in 196 PRB (Zhang et al. 2019) and according to Christian et al. (2019), the following four

197 criteria are considered to identify the occurrence of FD events in PRB: (1) a minimum

198 length of 3 SESR changes ( $\triangle$ SESR), equivalent to a length of four pentads (20 days),

199 (2) the final SESR should be below the 20th percentile of SESR values, (3) $\triangle$ SESR

200 should be below the 40th percentile between two pentads and no more one $\triangle$ SESR is

201 above the 40th percentile following a $\triangle$ SESR, and (4) the mean change in SESR

202 throughout the whole FD should be less than the 25th percentile of the changes in 
203 SESR. The first two criteria address the effects of FDs on environment, while the

204 latter two criteria emphasize the rapid intensification of FD. More detailed

205 explanations of the four criteria can be referred to Christian et al. (2019). In this study,

206 the minimum length of 20 days (four pentads) for criterion 1 is selected according to

207 the frequent characteristics of high-temperature heat waves in PRB (Zhang et al.

208 2019). Based on the above criteria, the occurrence of FD events is identified at each

209 grid point over the PRB during the vegetative growing season (April-November) for

210 the period 1953-2013.

211 Based on the Runs theory (Yevjevich 1967), three FD characteristics $(D, I, P)$ are

212 extracted from the FD events at each grid point over the PRB. $D$ refers to the total

213 pentads for a FD event. $P$ is defined as the absolute value of the minimum SESR

214 during a FD event. $I$ is the absolute mean change in SESR throughout the whole FD

215 event, which reflects uncontrollable and dramatic changes of environment.

\section{$216 \quad 3.3$ Mann-Kendall trend test}

217 The Mann-Kendall (M-K) test is a non-parametric statistical method for testing the 218 trend of hydrometeorological data (Dawood 2017; Kendall 1975; Mann 1945). The

219 M-K method has the advantages of not assuming any distribution forms for the data

220 and not being affected by interference from outliers, and is widely used for detecting

221 the significance of long-term trends in hydrometeorological variables (Gocic and

222 Trajkovic 2013; Li et al. 2021; Mekonen and Berlie 2020; Wu et al. 2018). In this

223 study, we apply the M-K method to detect the statistical significance of the trends in 
224 FD characteristics $(D, I$ and $P)$ at the $5 \%$ significance level $(a=0.05)$. The non-

225 parametric trend slope estimator method (Sen 1968) is used to estimate trend

226 magnitudes in FD characteristics.

\subsection{Marginal distribution}

228 Four different probability distribution functions (PDFs), namely gamma (GAM),

229 exponential (EXP), generalized extreme value (GEV) and lognormal distribution

230 (LOG), are used to fit FD characteristics (Table 1). We choose these PDFs, because

231 they are widely used in estimating the marginal probability distributions of

232 meteorological drought characteristics (Nabaei et al. 2019; Wu et al. 2021). The

233 parameters of each PDF are estimated using the maximum likelihood estimation

234 method (Xu et al. 2015). The RMSE and K-S test are used for goodness of fit tests to

235 select the best marginal distribution at the $95 \%$ significance level, that is, the

236 optimal marginal distribution is selected after passing the K-S test and having the

237 smallest RMSE (Wu et al. 2021). The formulas of the K-S test are expressed as

238 follows:

$$
K_{n}(x)=\frac{1}{n} \sum_{i=1}^{n} I_{[-\infty, x]}\left(X_{i}\right)
$$

$$
I_{[-\infty, x]}\left(X_{i}\right)=\left\{\begin{array}{l}
1, X_{i} \leq x \\
0, X_{i}>x
\end{array}\right.
$$

241 where $K_{n}(x)$ is the K-S statistic and $I_{[-\infty, x]}$ is an indicator function ranging from 0 242 to 1. 
244 Copula is a joint function that connects two or more marginal distribution functions

$245\left(F_{X}(x) F_{Y}(y)\right)$ from a joint distribution function $\left(F_{X, Y}(x, y)\right)$, which describes the

246 probability that the two or more variables are equal to or less than a given value (Sklar

247 1959). The general form of copula is expressed as (Nelsen 2006):

$$
F_{X, Y}(x, y)=C\left[F_{X}(x), F_{Y}(y)\right]=C[u,
$$

$$
\text { v] }
$$

250

where $u$ and $v$ are the marginal distribution functions of $X$ and $Y$, respectively. The copula functions can be classified to three forms: elliptical, Archimedean, and quadratic, and among them Archimedean copulas are widely used for hydrometeorological analyses ( Bisht et al. 2019; Thilakarathne and Sridhar 2017; Wu et al. 2021). In this study, three common Archimedean copula functions, including Clayton, Frank and Gumbel copulas (Table 2), are used to construct the joint distribution of three pairs of FD characteristics $(D-I, I-P, D-P)$ at each grid over the PRB. The K-S test and RMSE are used to assess the goodness fitting of copula functions.

\subsection{Return period}

For a single variable $(X)$ equal to or greater than a given value $(x)$, univariate return period $T(x)$ can be calculated as:

$$
T(x)=\frac{N}{n[1-F(x)]}
$$

where $N$ is the length of the study period (i.e., 61-yr in this study), $n$ is total number of FD events, and $F(x)$ is the marginal distribution of FD characteristic. 
264 In this study, two different joint probabilities $\left(P_{x \vee y}\right.$ and $\left.P_{x \wedge y}\right)$ of three pairs of FD 265 characteristics are considered (Shiau 2006; Nabaei et al. 2019):

$$
P_{x \vee y}=P(X>x \text { or } Y>y)=1-C\left(F_{X}(x), F_{Y}(y)\right)=1-
$$

$$
C(u, v)
$$

$$
P_{x \wedge y}=P(X>x, Y>y)=1-F_{X}(x)-F_{Y}(y)+C\left(F_{X}(x), F_{Y}(y)\right)=1-u-v+C(u, v)
$$

where the symbol $\vee$ denotes "union" ("or") and $\wedge$ denotes "intersection" ("and"). The occurrence return period, $T_{a}$ ) are expressed as follows:

$$
\begin{gathered}
T_{o}=\frac{N}{n[1-C(u, v)]} \\
T_{a}=\frac{N}{n[1-u-v+C(u, v)]}
\end{gathered}
$$

where $u$ and $v$ are the marginal distributions of FD characteristics, and $C(u, v)$ is the joint distribution of the pairs of FD characteristics.

\section{Results}

\subsection{Spatial and temporal trends in FD characteristics}

The spatial distributions of mean $D, I$ and $P$ as well as the frequency of FD events during 1953-2013 are displayed in Fig. 2. It is shown that the frequency of FD (events) is less than 20 in most parts of PRB and tends to decrease from the eastern ( $>$ $50)$ to western $(<10)$ regions (Fig. $2 a) . D$ is less than 22 days in almost the whole study basin (except for the PRD and the downstream of ERB, Fig. 2b). Similarly, $I$

283 tends to decrease from the east $(>0.7)$ to the west $(\sim 0.5)$ regions (Fig. $2 c)$. The range 284 of $P$ is $0.94 \sim 1.38$ over the PRB (Fig. 2 d), and smaller (larger) $P$ is found in the 
midstream of WRB and upstream of NRB (western WRB).

Fig. 3 displays the spatial distributions of the trend magnitudes in $D, I$ and $P$ over the study area during the period 1953-2013. As shown in Fig. 3a, a substantial spatial difference in the trend magnitudes of $D$ is found across the PRB (Fig. 3a). A decreasing trend in $D$ is observed in most parts of $\mathrm{PRB}$, with a significant decreasing 290 trend $(a<0.05)$ in the downstream of NRB and PRD. In contrast, an increasing trend 291 (not significant) in $D$ is found in the upper and middle reaches of WRB, the upstream of NRB and some parts of southeastern PRB (Fig. 3a). For $I$, a significant decreasing trend $(a<0.05)$ is concentrated in the middle and lower reaches of WRB and the upstream of NRB (down to 3.1). In contrast, the significant increasing trend appears only in western WRB and southern NRB (up to 2.39, Fig. 3b), which is generally the opposite of the increasing trend of $D$ (Fig. 3a). $P$ shows an increasing trend mainly in

297 the upstream and downstream of WRB and western NRB (up to 3.8), while the 298 decreasing trend is scattered in the northern and southern parts of middle WRB as 299 well as the downstream of NRB (the largest decline is $>2.8$, Fig. 3c).

\subsection{Selection of marginal distributions and bivariate Copulas}

301 The GAM, EXP, GEV and LOG are used to fit the marginal distributions of $D, I$ and $P$ 302 at each grid over PRB. The Clayton, Frank and Gumbel are used to fit the joint 303 probability distributions of $D-I, D-P$, and $P-I$. The best marginal distribution and 304 Copula at each grid are selected when it passes the K-S test and has the smallest 305 RMSE. The distributions of the best-fitted marginal distribution of each FD 
characteristic determined by the RMSE and K-S test are displayed in Fig. 4. It is

found that LOG is the best-fitted marginal distribution function of $D, I$ and $P$ for most of PRB, accounting for $88 \%, 53 \%$ and $70 \%$ of the total grids, respectively. For $D$, the percentage of grids identified by the EXP distribution is approximately $10 \%$, while for $I$ and $V$ the percentage of grids identified by the GEV distribution is approximately $47 \%$ and $27 \%$, respectively. In contrast, for $D(I$ and $V)$, almost no grids are identified

312 by the GEV (EXP) distribution. In addition, for all FD characteristics, almost no grids 313 are identified by the GAM distribution (except for some grids for $P$, Fig. 4c). Overall, 314 at the basin scale, GEV is the best-fitted marginal distribution function of $P$ in ERB, 315 while LOG is the best-fitted marginal distribution of all FD characteristics in WRB 316 and NRB. The spatial distributions of the best-fitted Copula functions of $D-I, D-P$, and $P-I$ are

318 displayed in Fig. 4d f. As shown, the best-fitted Copula functions of three pairs of FD 319 characteristics can be identified in all the grids over the PRB. Frank, Clayton, and 320 Gumbel are the best-fitted Copula functions accounting for $61.4 \%, 31.2 \%$, and $7.4 \%$ 321 for the joint $D-I$ PDFs, $67.3 \%, 24.5 \%$, and $8.2 \%$ for the joint $D-P$ PDFs, and $67.3 \%$, $32228.5 \%$, and $4.2 \%$ for the joint $P-I$ PDFs over the PRB. In contrast, very few grids are 323 identified by the Gumbel function for all three pairs of FD characteristics.

\section{$324 \quad$ 4.3 Joint PDF of FD characteristics}

325 The joint PDF at each grid point over the PRB is constructed using the best fitted 326 marginal distribution and copula function. The two-dimensional joint PDFs of $D-I, D-$ 
$P$ and $P-I$ in WRB, NRB and ERB are displayed in Fig. 5. As seen, when $D<20$ days

328 and $I<0.5$, the joint PDF of $D-I$ can be neglected in all basins. Similarly, the joint

329 PDF of $D<20$ days and $P<0.7,0.87$ and 0.92 also tends to be neglected in WRB,

$330 \mathrm{NRB}$ and ERB, respectively. In contrast, when $D$ increases from 20 to 40 days and $I$

331 increases from 0.5 to 1 , the joint PDF of $D-I$ sharply increases close to 1 in all basins.

332 When $D$ increases from 20 to 40 days and $P$ increases from 0.7 to $2,0.87$ to 2 and

3330.92 to 2 in WRB, NRB and ERB, respectively, the joint PDF of $D-P$ increases close

334 to 1 . Similarly, when $I$ increases from 0.5 to 1 and $P$ increases from 0.7 to $2,0.87$ to 2

335 and 0.92 to 2 , the joint PDF of $I-P$ increases close to 1 in WRB, NRB and ERB,

336 respectively. However, the increasing rate of joint PDF tends to decrease when $D>28$

337 days and $P>1.4$ in WRB, NRB and ERB. Also, the increasing rate of joint PDF tends

338 to decrease when $D>28$ days and $I>0.68,0.79,0.82$ respectively in WRB, NRB and

339 ERB.

340 It can be found by comparison that the joint PDFs of $D-I, D-P$ and $P-I$ tend to be

341 'fatter' in WRB and NRB than in ERB, suggesting a higher risk of FD in ERB than in

342 WRB and NRB. This is supported by Table 3, showing that the design values of $D$

343 corresponding to the same return periods $(10,20,50$, and 100a) are generally the

344 largest in ERB, followed by WRB and NRB. Similarly, the design values of $P$ and $I$

345 corresponding to the same return periods are the largest in ERB, followed by NRB

346 and WRB.

$347 \quad$ 4.4 Geographic pattern of $\boldsymbol{T}_{\mathbf{0}}$ 

row), and ERB (the third row) are displayed in Fig. 6. As shown, for a certain $I$ and $P$, the $T_{o}$ of $D-I$ and $D-P$ is the largest in WRB, followed by NRB and ERB, suggesting a higher probability of a smaller $D$ in WRB than in the other two basins, a consistent

352 finding with that in Fig. 2b. For a certain $I$ and $P$, the $T_{o}$ of $I-P$ is also the largest in WRB, followed by NRB and ERB, suggesting a higher probability of smaller $I$ and $P$ in WRB than in the other two basins, a consistent finding with that in Fig. $2 \mathrm{c}$ and d. It is also found that the $T_{o}$ tends to increase slowly $(<50-\mathrm{yr})$ and then fast $(>100-\mathrm{yr})$ with the increasing $D, I$ and $P$ in all three basins.

Four different design values of $D, I$ and $P$ corresponding to different univariate return periods $\left(10,20,50\right.$, and 100a) are used to compute the $T_{o}$ of $D-I, D-P$, and $P-I$ in WRB, NRB, and ERB (Table 3). For the same return periods, the $T_{o}$ of $D-I$ and $D-P$ is the largest in WRB, followed by NRB and ERB, while the $T_{o}$ of $P-I$ is the largest in NRB, followed by WRB and ERB. In addition, the $T_{o}$ of $P-I$ is larger than that of $D-I$ and $D-P$ in all basins.

Three specified thresholds of $D(D 1: 20 \mathrm{~d}, D 2: 25 \mathrm{~d}, D 3: 30 \mathrm{~d}), I(I 1: 25 \mathrm{th}, I 2: 50 \mathrm{th}, I 3$ : 75th percentile), and $P(I 1: 25$ th, $I 2: 50$ th, $I 3: 75$ th percentile) are used to calculate the $T_{o}$ at each grid point over the PRB. The spatial distributions of the $T_{o}$ of $D 1-I 1, D 2-I 2$, D3-I3, D1-P1, D2-P2, D3-P3, I1-P1, I2-P2 and I3-P3 are displayed in Fig. 7. As shown, the $T_{o}$ of $D 1-I 1, D 2-I 2, D 1-P 1, D 2-P 2, I 1-P 1$ and $I 2-P 2$ is less than 10 a in most parts of western PRB and less than 5a in eastern PRB. The $T_{o}$ of D3-I3 is in the 
range of 30 300a in southern ERB and PRD, and is greater than 300a in most of NRB and WRB (Fig. 7c). The $T_{o}$ of $D 3-P 3$ and $P 3-13$ is less than $5 \mathrm{a}$ in ERB and PRD, and

371 less than 30a in most of WRB (Fig. 7f), which is significantly smaller than the $T_{o}$ of D3-I3 (Fig. 7c).

\subsection{Geographic pattern of $T_{a}$}

The $T_{a}$ is calculated at the basin scale by equation (7b). The contour maps of $T_{a}$ of $D-I, D-P$, and $P-I$ in three basins (WRB, NRB, and ERB) are displayed in Fig. 8. For a certain $D, I$ and $P$, the $T_{a}$ of $D-I, D-P$, and $P-I$ is the smallest in ERB, suggesting a higher risk of FD in ERB compared with the other two basins. The $T_{a}$ of $D-I$ and $D-P$ is smaller (larger) in NRB than WRB when $D$ is less (larger) than 21 days, while the $T_{a}$ of $P-I$ is larger in WRB than NRB. The design values of FD characteristics and the

381 corresponding $T_{a}$ in three basins are shown in Table 3. For the same return periods $382\left(10,20,50\right.$ and 100a), the $T_{a}$ of $D-I$ is the largest in NRB, followed by ERB and $383 \mathrm{WRB}$, the $T_{a}$ of $D-P$ is the largest in ERB, followed by NRB and WRB, and the $T_{a}$ of $384 P-I$ is the largest in ERB, followed by WRB and NRB. In addition, the $T_{a}$ of $D-P$ is 385 larger than that of $D-I$ and $P-I$ in WRB and ERB, while in NRB the $T_{a}$ of $D-I$ is 386 significantly larger than that of $D-P$ and $P-I$.

387 Three specified thresholds of $D(D 1: 20 \mathrm{~d}, D 2: 25 \mathrm{~d}, D 3: 30 \mathrm{~d}), I(I 1: 25 \mathrm{th}, I 2: 50 \mathrm{th}, I 3$ : 388 75th percentile), and $P(I 1: 25$ th, $I 2: 50$ th, $I 3: 75$ th percentile) are used to calculate the $389 T_{a}$ at each grid point over the study basin. The spatial distributions of the $T_{a}$ of $D 1-I 1$, 
391 As shown in Fig. 9, the $T_{a}$ of $I 1-P 1, I 2-P 2, D 1-P 1$ and $D 1-I 1$ is less than 5a in eastern

392 PRB and larger than 10a in some parts of WRB. The areas with the $T_{a}$ of $I 1-P 1, I 2-P 2$, $393 \quad D 1-P 1$ and $D 1-I 1$ less than 5 a are decreased in order. For D2-I2 and D2-P2 (Fig. 9b 394 and e), the $T_{\mathrm{a}}$ is less than $30 \mathrm{a}$ in southeastern PRB, and larger than $300 \mathrm{a}$ in most parts 395 of WRB and NRB. For D3-I3, D3-P3 and I3-P3 (Fig. 9c, f and i), the $T_{\mathrm{a}}$ is larger than 396 300a in most parts of PRB, and the area with $T_{\mathrm{a}}$ larger than 300a is the largest for D3$397 \quad I 3$, followed by D3-P3 and P3-I3. In contrast, the $T_{\mathrm{a}}$ of $D 3-P 3$ and I3-P3 less than 30a 398 is concentrated only in southern PRD, southern ERB, and western and central WRB.

\section{Discussion}

400 Based on the GLDAS and observation data, we used four marginal distribution 401 functions (GAM, EXP, GEV, and LOG) and three Archimedean Copulas (Clayton, 402 Gumbel and Frank Copula) to explore the geographic pattern of bidimensional return 403 period $\left(T_{o}\right.$ and $\left.T_{a}\right)$ of the paired FD characteristics $(D-I, D-P$ and $P-I)$ over the PRB. It 404 was found that different FD characteristics usually follow different statistical 405 distributions, resulting in a large spatial variability in the best-fitted marginal 406 probability distributions of FD characteristics as well as the best-fitted copulas of the 407 paired FD characteristics over the study basin. This is generally consistent with the 408 previous studies on the probability distribution assessment of meteorological drought 409 characteristics at the global (Wu et al. 2021) and regional (Nabaei et al. 2019) scales. 410 Our results suggest that only one or few PDFs (or copula functions) were selected for 411 analysis may lead to inaccurate probability estimates of FD characteristics, because 
they may not be the best PDFs (or copula functions) of FD characteristics.

413 The analysis indicates a larger FD characteristic (Fig. 2) as well as a smaller joint

414 return period of FD characteristics in eastern PRB (mainly southern ERB and PRD)

415 (Fig. 7 and 9). In contrast, the smaller FD characteristic (Fig. 2) and larger joint return

416 period of FD characteristics are concentrated in western WRB (Fig. 7 and 9). This

417 suggests a high risk of FD in southern ERB and PRD and a lower risk of FD in

418 western WRB (Fig. 2, 7, and 9). Two key reasons might be responsible for the higher

419 FD risk in eastern PRB (mainly southern ERB and PRD). First, the plain areas in PRD

420 are mainly heavy population and dense cities, in which surface fluxes and ET are

421 highly sensitive to changes in soil moisture (Guo et al. 2006; Wei et al. 2016), easily

422 accelerating the continuous drying of the atmosphere and leading to a decrease in

423 SESR. In addition, the ERB is dominated by agricultural regions, which generally

424 have a shallower root zone and a high rate of ET (soil moisture depletion) with high

425 risk of short-term concurrent hot and dry extremes (Zhang et al. 2019). In contrast, the

426 lower risk of FD in western PRB (mainly western WRB) can be attributed to the high-

427 altitude terrain, where relatively sparse vegetation limits transpiration and causes ET

428 to be restricted (Pielke 2001).

429 Note that this study is subject to a few limitations. First, for FD identification, the

430 minimum length of 20 days (four pentads) is selected for the whole basin according to

431 the frequent characteristics of high-temperature heat waves in PRB (Zhang et al.

432 2019). For a certain region, changes in the threshold of the minimum $D$ would affect 
433 the number of FD events and the size of FD characteristics. On the other hand,

434 because FD characteristics have strong spatial variability (Fig. 2), it is reasonable to

435 believe that the threshold of the minimum $D$ of FD also has a strong spatial

436 variability. Therefore, it would be interesting in future work to explore the sensitivity

437 of the number of FD events and the size of FD characteristics to the threshold of the

438 minimum $D$ to determine the most suitable minimum $D$ of FD at each grid point over

439 the study basin. In addition, we also found that there are few FD events (less than 10

440 times) identified in western WRB (Fig. 2a). The relatively small sample size of FD

441 events may not be able to fully characterize the range of FD characteristics, which

442 may lead to inaccurate probability estimates of FD characteristics.

\section{Conclusions}

Based on the SESR-based method developed by Christian et al (2019), the occurrence

446 of FD events during the period $1953-2013$ was identified at each $0.25^{\circ} \times 0.25^{\circ}$ grid

447 point over the PRB. Three FD characteristics (i.e., duration $D$, intensity $I$, peak $P$ )

448 were extracted by the Runs theory. Four marginal distribution functions (Gamma,

449 Exponential, GEV and Lognormal) were used to fit $D, I$ and $P$, while three

450 Archimedean Copula functions (Clayton, Frank and Gumbel) were used for

451 generating the joint distributions of various paired FD characteristics. The spatio-

452 temporal variability of the two different joint return periods (union return period $T_{o}$

453 and co-occurrence return period $\left.T_{a}\right)$ of three pairs of FD characteristics $(D-I, D-P$ and 
$454 I-P$ ) over the PRB was quantitatively assessed using copula-based models. The main 455 findings drawn from this study are summarized as follows.

456 (1) Different FD characteristics usually follow different statistical distributions, 457 resulting in a large spatial variability in the best-fitted marginal probability 458 distributions of FD characteristics as well as the best-fitted copulas of the paired FD 459 characteristics. Overall, LOG is the best-fitted marginal distribution function of $D, I$ 460 and $P$ for most of PRB, accounting for $88 \%, 53 \%$ and $70 \%$ of the total area of PRB, 461 respectively. Frank and Clayton are the best-fitted Copula of the joint PDFs of three 462 pairs of FD characteristics for most of the PRB, accounting for $61.4 \% \sim 67.3 \%$ and $46324.5 \% \sim 28.5 \%$ of the total area of PRB, respectively.

464 (2) During the period 1953-2013, the FD events are more frequent in eastern PRD 465 and southern ERB ( $>40$ events) than in western WRB ( $<10$ events). Similarly, larger $466 D$ and $I$ are observed in PRD and southern ERB, while larger $P$ is observed in western 467 WRB and southern ERB. The trend analysis shows that a decreasing trend in $D$ is 468 observed in most of PRB (especially PRD). I shows a significant decreasing 469 (increasing) trend in the middle and lower reaches of WRB and the upstream of NRB 470 (western WRB and southern NRB), while $P$ shows an increasing (decreasing) trend 471 mainly in the downstream of WRB (central WRB and southern NRB).

472 (3) The return period of $D$ is the smallest in ERB, followed by WRB and NRB. The 473 return periods of $P$ and $I$ are the smallest in ERB, followed by NRB and WRB. The $T_{o}$ 474 and $T_{a}$ show generally similar spatial patterns over the PRB, but the magnitude of $T_{a}$ is 
475 significantly larger than that of $T_{o}$. The $T_{o}$ and $T_{a}$ of $D-I, D-P$, and $P-I$ are both

476 smaller in eastern PRB than western PRB, resulting the highest risk of FD in ERB

477 followed by NRB and WRB.

478

480 Declarations

481 Funding

482 See Acknowledgements.

483 Acknowledgements

484 This research was supported by funding from the National Natural Science

485 Foundation of China (Grant No. 51909106, 51879108), the Natural Science

486 Foundation of Guangdong Province, China (Grant No. 2018A030310653), the high-

487 level talent project for the "Pearl River Talent Plan" of Guangdong Province (Grant

488 No. 2017GC010397), and the Youth Innovative Talents Project for Guangdong

489 Colleges and Universities (Grant No. 2017KQNCX010).

\section{Data availability}

491 The daily ET data of the study area were driven from the GLDAS-2.0 forcing data

492 (https://ldas.gsfc.nasa.gov/). The daily meteorological data were provided by the

493 National Meteorological Information Center (http://data.cma.cn). 


\section{Authors' contributions}

496 All authors contributed to the study conception and design.

497 Bei Chen provided the methodology, analyzed the data, wrote the code and the

498 original draft. Chuanhao $\mathrm{Wu}$ provided the methodology, funding acquisition, and

499 revised the manuscript. Pat J.-F. Yeh provided the writing guidance and review. Jiayun

500 Li provided the guidance of conceptualization and writing. Wenhan Lv collected the

501 data. Jin Zhao revised the writhing grammer.

502 Compliance with ethical standards

503 Conflicts of interest/Competing interests

504 We have no conflict of interest.

\section{Ethics approval}

506 We confirm that this article is original research and has not been published or

507 presented previously in any journal or conference in any language (in whole or in 508 part).

\section{Consent to participate and consent for publication}

510 We have consent to participate and publish.

\section{References}

512 Allen CD, Macalady AK, Chenchouni H, Bachelet D, McDowell N, et al (2010) A 
513 global overview of drought and heat-induced tree mortality reveals emerging climate

514 change risks for forests. For. Ecol. Manag 259(4): 660-684.

515 https://doi.org/10.1016/i.foreco.2009.09.001

516 Allan RP, Soden BJ (2008) Atmospheric warming and the amplification of precipitation

517 extremes. Science 321(5895): 1481-1484.

$518 \quad$ http://doi.org./10.1126/scince. 1160787

519 Ayantobo OO, Li Y, Song S, Javed T, Yao N (2018) Probabilistic modelling of drought

520 events in China via 2-dimensional joint copula. J. Hydrol 559: 373-391.

$521 \quad$ https://doi.org/10.1016/j.jhydrol.2018.02.022

522 Bi HY, Ma JW, Zheng WJ, Zeng JY (2016) Comparison of soil moisture in GLDAS

523 model simulations and in situ observations over the Tibetan plateau. J. Geophys. Res.

524 Atmos 121(6): 2658-2678. https://doi.org/10.1002/2015JD024131

525 Bisht DS, Sridhar V, Mishra A, Chatterjee C, Raghuwanshi NS (2019) Drought

526 characterization over India under projected climate scenario. Int J Climatol 39(4):

527 1889-1911. https://doi.org/10.1002/joc.5922

528 Christian JI, Basara JB, Otkin JA, Hunt ED, Wakefield RA (2019) A methodology for 529 flash drought identification: Application of flash drought frequency across the United $530 \quad$ States. J Hydrometeorol 20(5): 833-846.

531 https://doi.org/10.1175/JHM-D-18-0198.1

532 Das SK, Maity R (2015) A hydrometeorological approach for probabilistic simulation 533 of monthly soil moisture under bare and crop land conditions. Water Resour. Res 51(4): 534 2336-2355. https://doi.org/10.1002/2014WR016043 
535 Dawood M (2017) Spatio-statistical analysis of temperature fluctuation using Mann-

536 Kendall and Sen's slope approach. Clim. Dyn 48 (3-4): 783-797.

$537 \quad$ http://dx.doi.org/10.1007/s00382-016-3110-y

538 Dracup JA, Lee KS, Paulson EG (1980) On the definition of droughts. Water Resour.

539 Res 16(2): 297-303. https://doi.org/10.1029/WR016i002p00297

540 Fontaine MM, Steinemann AC (2009) Assessing vulnerability to natural hazards:

541 Impact-based method and application to drought in Washington State. Nat Hazards

542 Rev 10(1): 11-18. https://doi.org/10.1061/(ASCE)1527-6988(2009)10:1(11)

543 Fischer T, Gemmer M, Su B, Scholten T (2012) Long-term meteorological and 544 hydrological dryness and wetness conditions in the Zhujiang River Basin, South China. 545 Hydrology and Earth System Sciences Discussions, 9(9): 10525-10562.

546 Ford TW, McRoberts DB, Quiring SM, Hall RE (2015) On the utility of in situ soil 547 moisture observations for flash drought early warning in Oklahoma, USA. Geophys.

548 Res. Lett 42(22): 9790-9798. https://doi.org/10.1002/2015GL066600

549 Ford TW, Labosier CF (2017) Meteorological conditions associated with the onset of 550 flash drought in the eastern United States. Agric For Meteorol 247: 414-423. $551 \quad$ https://doi.org/10.1002/2015GL066600

552 Gocic M, Trajkovic S (2013) Analysis of changes in meteorological variables using 553 Mann-Kendall and Sen's slope estimator statistical tests in Serbia. Glob Planet Chang 554 100:172-182. https://doi.org/10.1016/j.gloplacha.2012.10.014

555 Guo Z, Dirmeyer PA, Koster RD, Bonan G, Chan E, Cox P, et al (2006). GLACE: the 556 global land - atmosphere coupling experiment. Part II: analysis. J Hydrometeorol 7: 
558 Jha S, Das J, Goyal MK (2019) Assessment of risk and resilience of terrestrial

559 ecosystem productivity under the influence of extreme climatic conditions over India.

560 Sci. Rep 9(1): 1-12. https://doi.org/10.1038/s41598-019-55067-0

561 Jha VB, Gujrati A, Singh RP (2020) Copula based analysis of meteorological drought

562 and catchment resilience across Indian river basins. Int J Climatol 41, E1137-E1151.

563 https://doi.org/10.1002/joc.6758

564 Ji L, Senay GB, Verdin JP (2015) Evaluation of the Global Land Data Assimilation

565 System (GLDAS) air temperature data products. J Hydrometeorol 16(6), 2463-2480.

$566 \quad$ https://doi.org/10.1175/JHM-D-14-0230.1

567 Kendall MG (1975) Rank correlation methods. 4th edition.

568 Kolmogorov A (1933) Sulla determinazione empirica di una legge di distribuzione.

569 Giornale dell'Istituto Italiano degli Attuari, 4: 83-91.

570 Koster RD, Schubert SD, Wang H, Mahanama SP, DeAngelis AM (2019) Flash drought

571 as captured by reanalysis data: Disentangling the contributions of precipitation deficit

572 and excess evapotranspiration. J Hydrometeorol 20(6): 1241-1258.

$573 \quad$ https://doi.org/10.1175/JHM-D-18-0242.1

574 Lee T, Modarres R, Ouarda TBMJ (2013) Data-based analysis of bivariate copula tail

575 dependence for drought duration and severity. Hydrol Process 27(10): 1454-1463.

$576 \quad$ https://doi.org/10.1002/hyp.9233

577 Liu LL, Jiang T, Xu JG, Zhai JQ, Luo Y (2012) Responses of hydrological processes to 578 the climate change in the Zhujiang River basin in the 21 st century. Adv. Clim. Chang. 
Li J, Wang ZL, Wu XS, Guo SL, Chen XH (2020) Flash droughts in the Pearl River

581 Basin, China: Observed characteristics and future changes. Sci. Total Environ 707:

582 136074. https://doi.org/10.1016/j.scitotenv.2019.136074

583 Liu Y, Zhu Y, Zhang LQ, Ren LL, Yuan F, Yang XL, Jiang SH (2020) Flash drought

584 characterization over China: From a perspective of the rapid intensification rate. Sci.

585 Total Environ, 704.https://doi.org/10.1016/j.scitotenv.2019.135373

586 Li JY, Wu CH, Xia CA, Yeh PJF, Hu BX, Huang GR (2021) Assessing the responses of 587 hydrological drought to meteorological drought in the Huai River Basin, China. 588 Theoretical and Applied Climatology, 144(3): 1043-1057.

589 https://doi.org/10.1007/s00704-021-03567-3

590 Mann HB (1945) Nonparametric test against trend. Econometrica: Journal of the 591 econometric society 13(3): 245-259. https://doi.org/10.2307/1907187

592 Mahrt L, Michael Ek (1984) The Influence of atmospheric stability on potential 593 evaporation. J Appl Meteorol Climatol 23(2): 222-234.

594 https://doi.org/10.1175/1520-0450(1984)023<0222:TIOASO >2.0.CO;2

595 Ma MW, Song SB, Ren LL, Jiang SH, Song JL (2013) Multivariate drought 596 characteristics using trivariate Gaussian and Student t copulas. Hydrol Process 27(8): 597 1175-1190. https://doi.org/10.1002/hyp.8432

598 Mekonen AA, Berlie AB (2020) Spatiotemporal variability and trends of rainfall and 599 temperature in the Northeastern Highlands of Ethiopia. Environ. Earth Sci 6(1): 285600 300. https://doi.org/10.1007/s40808-019-00678-9 
601 Mishra AK, Singh VP (2010) A review of drought concepts. Journal of Hydrology, 602 391(1-2): 202-216. https://doi.org/10.1016/j.jhydrol.2010.07.012

603 Mo KC, Lettenmaier DP (2015) Heat wave flash droughts in decline. Geophys. Res.

604 Lett 42(8): 2823-2829. https://doi.org/10.1002/2015GL064018

605 Mo KC, Lettenmaier DP (2016) Precipitation deficit flash droughts over the United $606 \quad$ States. J Hydrometeorol 17(4): 1169-1184.

607 https://doi.org/10.1175/JHM-D-15-0158.1

608 Nabaei S, Sharafati, A, Yaseen ZM, Shahid S (2019) Copula based assessment of 609 meteorological drought characteristics: regional investigation of Iran. Agric For 610 Meteorol 276, 107611. https://doi.org/10.1016/j.agrformet.2019.06.010

611 Nelsen RB (2006) An introduction to copulas, ser. Lect. Notes Stat. Springer, New York.

612 Osman M, Zaitchik BF, Badr HS, Christian JI, Tadesse T, Otkin JA, Anderson MC 613 (2021) Flash drought onset over the contiguous United States: sensitivity of 614 inventories and trends to quantitative definitions. Hydrol Earth Syst Sci 25(2): 565615 581. https://doi.org/10.5194/hess-25-565-2021

616 Otkin JA, Shafer M, Svoboda M, Wardlow B, Anderson MC (2014) Facilitating the use 617 of drought early warning information through interactions with agricultural 618 stakeholders. Bull Am Meteorol Soc 96(7), 1073-1078.

619 https://doi.org/10.1175/BAMS-D-14-00219.1

620 Otkin JA, Anderson MC, Hain C, Svoboda M (2015) Using temporal changes in 621 drought indices to generate probabilistic drought intensification forecasts. Journal of 622 Hydrometeorology, 16(1), 88-105. https://doi.org/10.1175/JHM-D-14-0064.1 
623 Otkin JA, Svoboda M, Hunt ED, Ford TW, Andersoson MC, Basara JB (2018) Flash

624 droughts: A review and assessment of the challenges imposed by rapid-onset droughts

625 in the United States. Bull Am Meteorol Soc 99(5): 911-919.

626 https://doi.org/10.1175/BAMS-D-17-0149.1

627 Park J, Choi M (2015) Estimation of evapotranspiration from ground-based 628 meteorological data and global land data assimilation system (GLDAS). Stoch 629 Environ Res Risk Assess 29(8): 1963-1992.

630 https://doi.org/10.1007/s00477-014-1004-2

631 Penman HL (1948) Natural evaporation from open water, bare soil and grass.

632 Proceedings of the Royal Society of London. Series A, Mathematical and Physical

633 Sciences, 193(1032), 120-145. https://doi.org/10.1098/rspa.1948.0037

634 Pielke RA (2001) Influence of the spatial distribution of vegetation and soils on the 635 prediction of cumulus convective rainfall. Rev. Geophys 39: $151-177$.

636 https://doi.org/10.1029/1999RG000072

637 Qu YP, Lyu J, Zhang WB, Su ZC, Li Z (2018) Progress in research on historical extreme 638 drought in China. Adv Water Resour 29 (2): 283-292.

639 doi: $10.14042 /$ j.cnki.32.1309.2018.02.016

640 Rahmstorf S, Coumou D (2011) Increase of extreme events in a warming world.

641 Proceedings of the National Academy of Sciences of the United States of America,

642108 (44): 17905-17909. https://doi.org/10.1073/pnas.1101766108

643 Rana A, Moradkhani H, Qin Y (2017) Understanding the joint behavior of temperature 644 and precipitation for climate change impact studies. Theor. Appl. Climatol 129(1-2): 
646 Renard B, Lang M (2007) Use of a Gaussian copula for multivariate extreme value 647 analysis: Some case studies in hydrology. Adv Water Resour 30(4):897-912.

$648 \quad$ https://doi.org/10.1016/j.advwatres.2006.08.001

649 Rodell M, Houser PR, Jambor U, Gottschalck J, Mitchell K, et al (2004) The global 650 land data assimilation system. Bull Am Meteorol Soc 85(3): 381-394.

651 https://doi.org/10.1175/BAMS-85-3-381

652 Salvadori G, Michele CD (2004) Frequency analysis via copulas: Theoretical aspects

653 and applications to hydrological events. Water Resour. Res 40(12).

654 https://doi.org/10.1029/2004WR003133

655 Sen PK (1968) Estimates of the regression coefficient based on Kendall's tau. J Am 656 Stat Assoc 63:1379-1389. https://doi.org/10.1080/01621459.1968.10480934

657 Shiau JT (2006) Fitting drought duration and severity with two-dimensional copulas.

658 Water Resour. Manag 20(5): 795-815. https://doi.org/10.1007/s11269-005-9008-9

659 Shiau JT, Modarres R (2009) Copula-based drought severity-duration-frequency 660 analysis in Iran. Meteorol. Appl 16(4): 481-489. https://doi.org/10.1002/met.145

661 Sharma A, Goyal MK (2020) Assessment of drought trend and variability in India using 662 wavelet transform. Hydrol Sci J 65(9): 1539-1554.

663 https://doi.org/10.1080/02626667.2020.1754422

664 Sklar A (1959) Fonctions de répartition à n dimensions et leurs marges. Publ. Inst. Stat.

665 Univ. Paris 8, 229-231. https://doi.org/10.1007/978-3-642-33590-7

666 Smirnov N (1948) Table for estimating the goodness of fit of empirical distributions. 
668 Tang YH, Chen XH (2015) Multi-scale spatio-temporal characteristics and influence of 669 precipitation variation in Zhujiang River basin during the last 50 years. Scientia 670 Geographica Sinica, 35(4), 476-482.

671 Thilakarathne M, Sridhar V (2017) Characterization of future drought conditions in the 672 Lower Mekong River Basin. Weather. Clim. Extremes 17: 47-58.

673 https://doi.org/10.1016/j.wace.2017.07.004

674 Tomas-Burguera M, Vicente-Serrano SM, Peña-Angulo D, Domínguez-Castro F, 675 Noguera I, E1 Kenawy A (2020) Global characterization of the varying responses of 676 the standardized precipitation evapotranspiration index to atmospheric evaporative 677 demand. J. Geophys. Res. Atmos. 125(17). https://doi.org/10.1029/2020JD033017

678 Trenberth KE, Dai A, Van Der Schrier G, Jones PD, Barichivich J, Briffa KR, Sheffield $679 \mathrm{~J}$ (2014) Global warming and changes in drought. Nat Clim Chang 4(1), 17-22. $680 \quad$ https://doi.org/10.1038/nclimate2067

681 Vicente-Serrano SM (2016) Foreword: Drought complexity and assessment under 682 climate change conditions. Cuadernos de investigación geográfica 42(1): 7-11. $683 \quad$ https://doi.org/10.18172/cig.2961

684 Wang LY, Yuan X, Xie ZH, Wu PL, Li YH (2016) Increasing flash droughts over China 685 during the recent global warming hiatus. Sci. Rep 6, 30571.

686 https://doi.org/10.1038/srep30571

687 Wang YM, Yuan X (2021) Anthropogenic speeding up of south China flash droughts as 688 exemplified by the 2019 summer - autumn transition season. Geophys. Res. Lett. 
690 Wee P, Shitan M (2013) Modelling rainfall duration and severity using copula. Sri

691 Lankan Journal of Applied Statistics, 14(1).

692 Wei J, Su H, Yang ZL (2016) Impact of moisture flux convergence and soil moisture on 693 precipitation: a case study for the southern United States with implications for the 694 globe. Clim. Dyn, 46: 467 - 481. https://doi.org/10.1007/s00382-015-2593-2

695 Wu CH, Hu BX, Huang G, Wang P, Xu K (2018) Responses of runoff to historical and 696 future climate variability over China. Hydrol Earth Syst Sci 22:1971-1991. 697 https://doi.org/10.5194/hess-22-1971-2018

698 Wu CH, Yeh PJF, Chen YY, Lv WH, Hu BX, Huang GR (2021) Copula-based risk 699 evaluation of global meteorological drought in the 21 st century based on CMIP5 700 multi-model ensemble projections. J. Hydrol. 598.

701 https://doi.org/10.1016/j.jhydrol.2021.126265

702 Xia J, Wei S (2016) Perspective on water security issue of changing environment in 703 China. J. Hydraul. Eng 47(3): 292-301.

704 Xu K, Yang DW, Xu XY, Lei HM (2015) Copula based drought frequency analysis 705 considering the spatio-temporal variability in Southwest China. J. Hydrol 527: 630706 640. https://doi.org/10.1016/j.jhydrol.2015.05.030

707 Yan D, Ren L, Wang G, Lin Q, Xiao W, Qin T (2016) Initiatives on evolution of 708 terrestrial water cycle and its role in global change. Adv Water Resour 27(6): 935-942. 709 Yevjevich VM (1967) An objective approach to definitions and investigations of 710 continental hydrologic droughts. Hydrol. Pap. Colorado State Univ. no. 23. 
711 Yin YH, Ma DY, Wu SH, Pan T (2015) Projections of aridity and its regional variability

712 over China in the mid-21st century. Int J Climatol 35(14): 4387-4398.

$713 \quad$ https://doi.org/10.1002/joc.4295

714 Yuan X, Wang L, Wu P, Ji P, Sheffield J, Zhang M (2019) Anthropogenic shift towards

715 higher risk of flash drought over China. Nat. Commun.10(1):1-8.

716 https://doi.org/10.1038/s41467-019-12692-7

717 Zhang L, Singh VP (2007) Bivariate rainfall frequency distributions using Archimedean

718 copulas. J. Hydrol, 332(1-2), 93-109.

719 https://doi.org/10.1016/j.jhydrol.2006.06.033

720 Zhang Q, Xiao MZ, Singh VP, Chen XH (2013) Copula-based risk evaluation of

721 hydrological droughts in the East River basin, China. Stoch Environ Res Risk Assess

722 27(6): 1397-1406. https://doi.org/10.1007/s00477-012-0675-9

723 Zhang YQ, You QL, Chen CC, Jing G, Adnan M (2018) Evaluation of downscaled

724 CMIP5 coupled with VIC model in simulating flash droughts in a humid subtropical

725 basin, China. J. Clim 31(31): 1075-1090. https://doi.org/10.1175/JCLI-D-17-0378.1

726 Zhang $\mathrm{HY}, \mathrm{Wu} \mathrm{CH}, \mathrm{Hu}, \mathrm{BX}$ (2019) Recent intensification of short-term concurrent hot

727 and dry extremes over the Pearl River basin, China. Int J Climatol 39: 4924-4937.

728 https://doi.org/10.1002/joc.6116

729 Zhu Y, Liu Y, Wang W, Yuan F, Ma MW, Yin YX (2021) Analysis of spatial-temporal 730 characteristics of flash drought and slowly-evolving drought using soil moisture 731 percentile. Transactions of the Chinese Society of Agricultural Engineering 732 (Transactions of the CSAE), 37(2): 114-122. 
734 Table 1. Univariate marginal distribution functions used in this study.

735 Table 2. Archimedean Copulas used in this study. $u$ and $v$ are the marginal distribution 736 functions; $\theta$ denotes the parameter of Copula.

737 Table 3. The design values of FD characteristics and their joint return periods in three 738 basins.

739 Fig. 1 The location of the Pearl River basin and the distribution of meteorological 740 stations.

741 Fig. 2 Spatial distributions of (a) the number of FD occurrences and mean (b) $D$ (in 742 days), (c) $I$, and (d) $P$ over the PRB during 1953-2013.

743 Fig. 3 Spatial distributions of the trend magnitudes in (a) $D$ (in days), (b) $I$, and (c) $P$ 744 over the PRB during 1953-2013. Significant increasing (decreasing) trends $(p<0.05)$ 745 are denoted by white regular triangles (green inverted triangles).

746 Fig. 4 Spatial distributions of the best-fitted marginal distribution functions of (a) $D$, 747 (b) $I$, and (c) $P$ as well as the best-fitted copula functions of (d) $D-I$, (e) $D-P$, and (f) $P$ 748 I over the PRB.

749 Fig. 5 Two-dimensional joint distribution maps of $D-I, D-P$, and $P-I$ in WRB (the first 750 row), NRB (the second row), and ERB (the third row).

751 Fig. 6 The contour maps of the joint return period $\left(T_{o}\right)$ (in years) of $D-I, D-P$, and $P-I$ 752 in WRB (the first row), NRB (the second row), and ERB (the third row).

753 Fig. 7 Spatial distributions of $T_{o}$ (in years) of (a) D1-I1, (b) D2-I2, (c) D3-I3, (d) D1754 P1, (e) D2-P2, (f) D3-P3, (g) I1-P1, (h) I2-P2, and (i) I3-P3 over the PRB.

755 Fig. 8 The contour maps of the joint return period $\left(T_{a}\right)$ (in years) of $D-I, D-P$, and $P-I$ 756 in WRB (the first row), NRB (the second row), and ERB (the third row).

757 Fig. 9 Spatial distributions of $T_{a}$ (in years) of (a) $D 1-I 1$, (b) $D 2-I 2$, (c) $D 3-I 3$, (d) $D 1$ 758 P1, (e) D2-P2, (f) D3-P3, (g) I1-P1, (h) I2-P2, (i) I3-P3 over the PRB. 
Table 1. Univariate marginal distribution functions used in this study.

\begin{tabular}{ccc}
\hline Distribution & PDF & Parameter \\
Gamma & $F(x)=\frac{\beta^{-\alpha}}{\Gamma(\alpha)} \int_{0}^{x} t^{\alpha-1} e^{-t / \beta} d t$ & $\alpha, \beta$ \\
Exponential & $F(x)=1-\exp (-(x-\xi) / \alpha)$ & $\alpha, \xi$ \\
GEV & $F(x)=\exp \left(-\exp \left(k^{-1} \ln \left(1-\frac{k(x-\xi)}{\alpha}\right)\right)\right), \xi$ \\
Lognormal & $F(x)=\frac{1}{x \sigma \sqrt{2 \pi}} \exp \left\{-\frac{(\ln x-\mu)^{2}}{2 \sigma^{2}}\right\}$ \\
\hline
\end{tabular}


Table 2. Archimedean Copulas used in this study. $u$ and $v$ are the marginal distribution functions; $\theta$ denotes the parameter of Copula.

\begin{tabular}{lcc}
\hline Copulas & Function & Range \\
\hline Clayton & $\max \left(\left[u^{-\theta}+v^{-\theta}-1\right]^{-1 / \theta}, 0\right)$ & $(-\infty, \infty)$ \\
Frank & $-\frac{1}{\theta} \ln \left[1+\frac{\left(\mathrm{e}^{-\theta u}-1\right)\left(\mathrm{e}^{-\theta v}-1\right)}{\left(\mathrm{e}^{-\theta}-1\right)}\right]$ & {$[1, \infty)$} \\
Gumbel & $\exp \left(-\left[(-\ln u)^{\theta}+(-\ln v)^{\theta}\right]\right)^{1 / \theta}$ & {$[1,0$} \\
\hline
\end{tabular}


Table 3. The design values of FD characteristics and their joint return periods in three basins.

\begin{tabular}{|c|c|c|c|c|c|c|c|c|c|c|}
\hline \multirow{2}{*}{ Basins } & \multirow{2}{*}{$\mathrm{T} / \mathrm{a}$} & \multirow{2}{*}{$\mathrm{Do} / \mathrm{d}$} & \multirow{2}{*}{ Io } & \multirow{2}{*}{ Po } & \multicolumn{2}{|c|}{ Do-Io } & \multicolumn{2}{|c|}{ Do-Po } & \multicolumn{2}{|c|}{ Po-Io } \\
\hline & & & & & $T_{o} / \mathrm{a}$ & $T_{a} / \mathrm{a}$ & $T_{o} / \mathrm{a}$ & $T_{a} / \mathrm{a}$ & $T_{o} / \mathrm{a}$ & $T_{a} / \mathrm{a}$ \\
\hline \multirow{4}{*}{ WRB } & 10 & 18.84 & 0.57 & 0.78 & 9.70 & 10.32 & 9.63 & 10.39 & 9.84 & 10.16 \\
\hline & 20 & 21.70 & 0.61 & 0.99 & 16.13 & 26.31 & 15.70 & 27.55 & 17.57 & 23.22 \\
\hline & 50 & 23.61 & 0.63 & 1.15 & 32.34 & 110.17 & 31.51 & 120.97 & 35.85 & 82.58 \\
\hline & 100 & 24.72 & 0.65 & 1.25 & 57.86 & 368.15 & 56.84 & 415.31 & 62.62 & 248.14 \\
\hline \multirow{4}{*}{ NRB } & 10 & 20.70 & 0.69 & 1.17 & 6.26 & 24.84 & 7.47 & 15.12 & 9.49 & 10.57 \\
\hline & 20 & 21.29 & 0.74 & 1.24 & 11.28 & 88.30 & 12.79 & 45.91 & 17.66 & 23.05 \\
\hline & 50 & 21.90 & 0.79 & 1.32 & 26.30 & 505.98 & 28.02 & 231.96 & 37.75 & 74.03 \\
\hline & 100 & 22.29 & 0.82 & 1.38 & 51.31 & 1959.7 & 53.11 & 853.84 & 66.16 & 204.70 \\
\hline \multirow{4}{*}{ ERB } & 10 & 23.44 & 0.78 & 1.30 & 7.16 & 16.57 & 6.85 & 18.49 & 8.61 & 11.93 \\
\hline & 20 & 24.81 & 0.84 & 1.36 & 12.67 & 47.41 & 12.22 & 55.15 & 15.41 & 28.47 \\
\hline & 50 & 26.34 & 0.89 & 1.43 & 28.13 & 224.65 & 27.52 & 272.87 & 32.62 & 107.07 \\
\hline & 100 & 27.37 & 0.93 & 1.46 & 53.33 & 801.30 & 52.65 & 993.99 & 58.83 & 333.19 \\
\hline
\end{tabular}




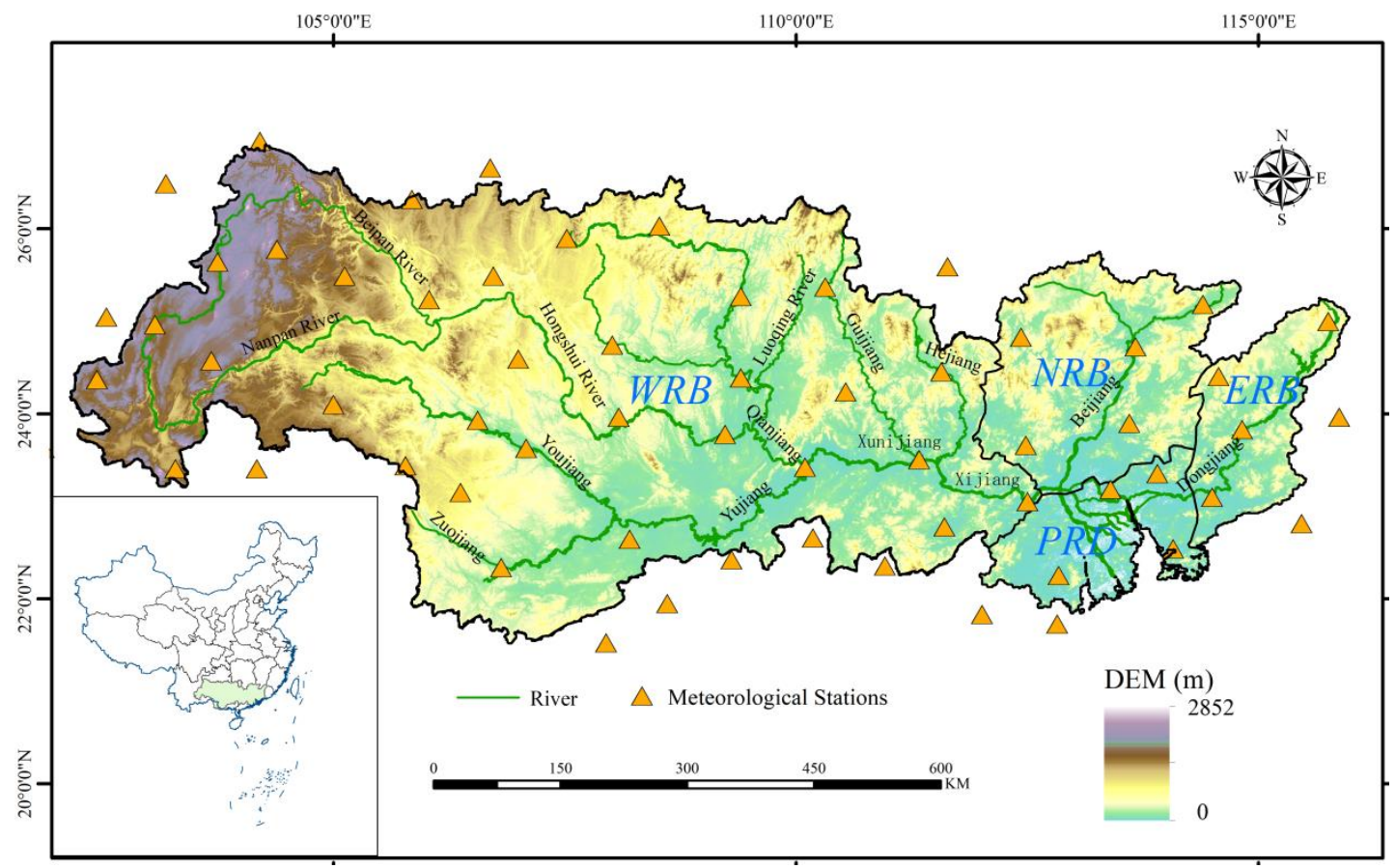

Fig. 1 The location of the Pearl River basin and the distribution of meteorological stations 

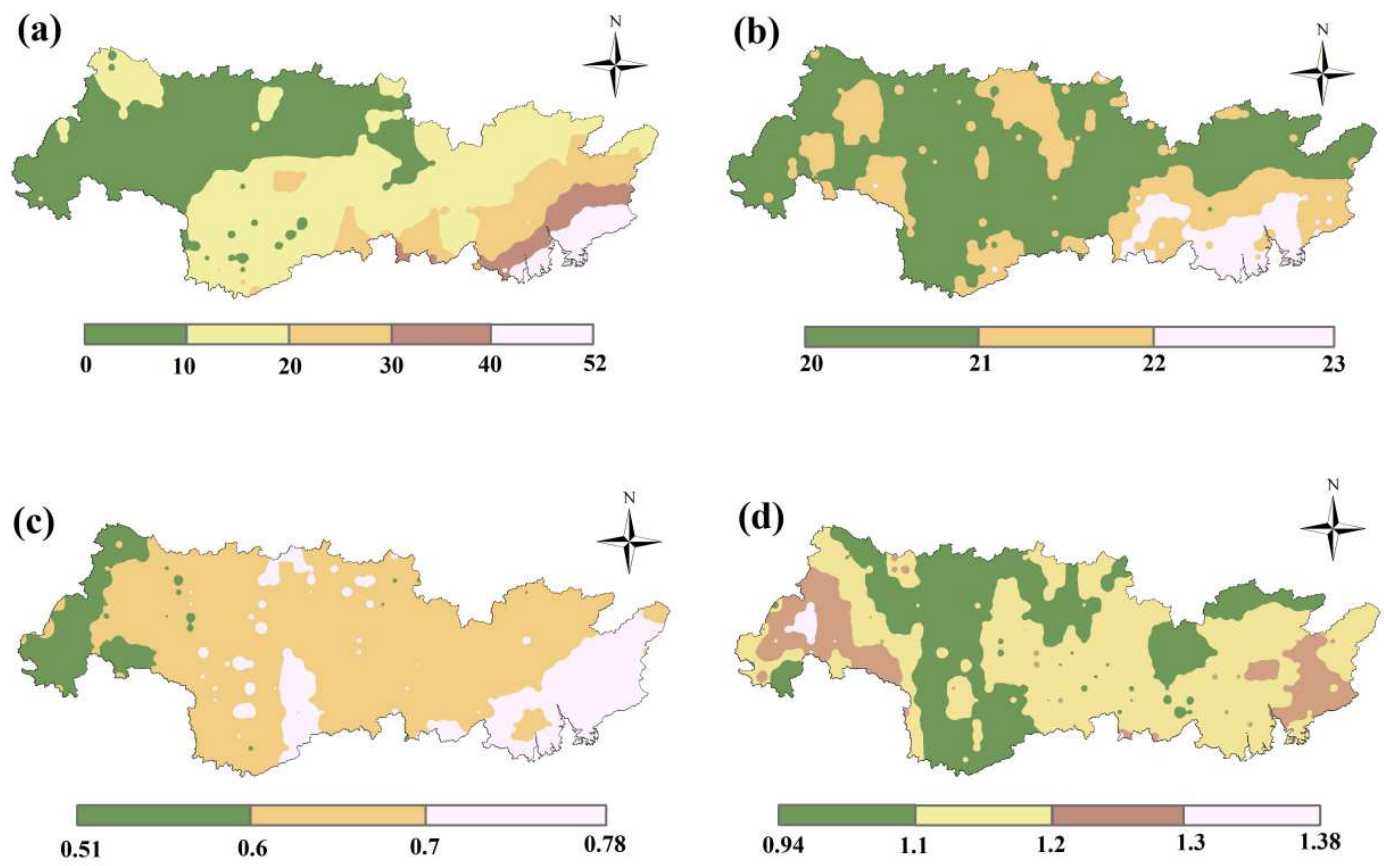

Fig. 2 Spatial distributions of (a) the number of FD occurrences and mean (b) $D$ (in days), (c) $I$, and (d) $P$ over the PRB during 1953-2013 


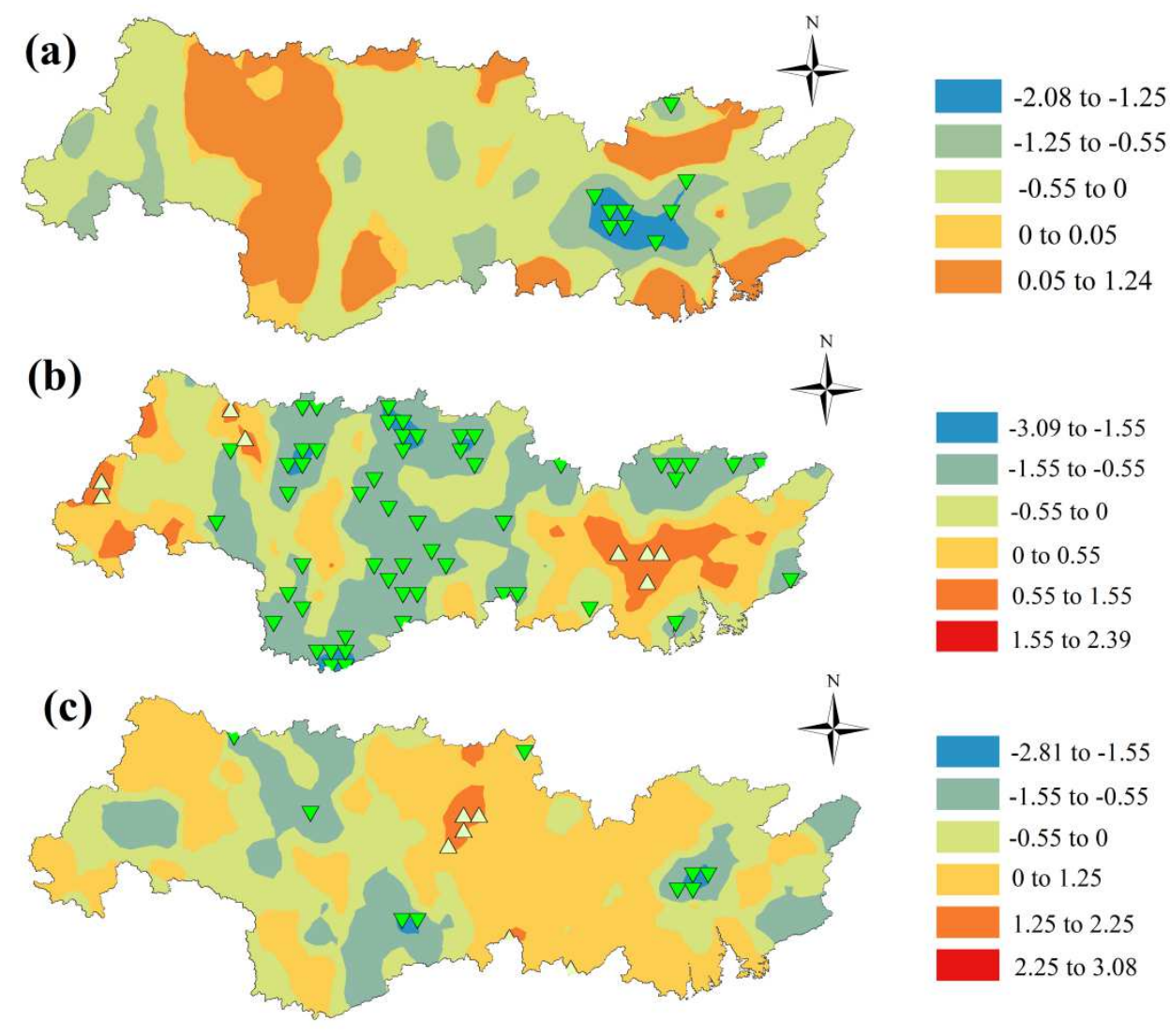

Fig. 3 Spatial distributions of the trend magnitudes in (a) $D$ (in days), (b) $I$, and (c) $P$ over the PRB during 1953-2013. Significant increasing (decreasing) trends $(p<0.05)$ are denoted by white regular triangles (green inverted triangles) 

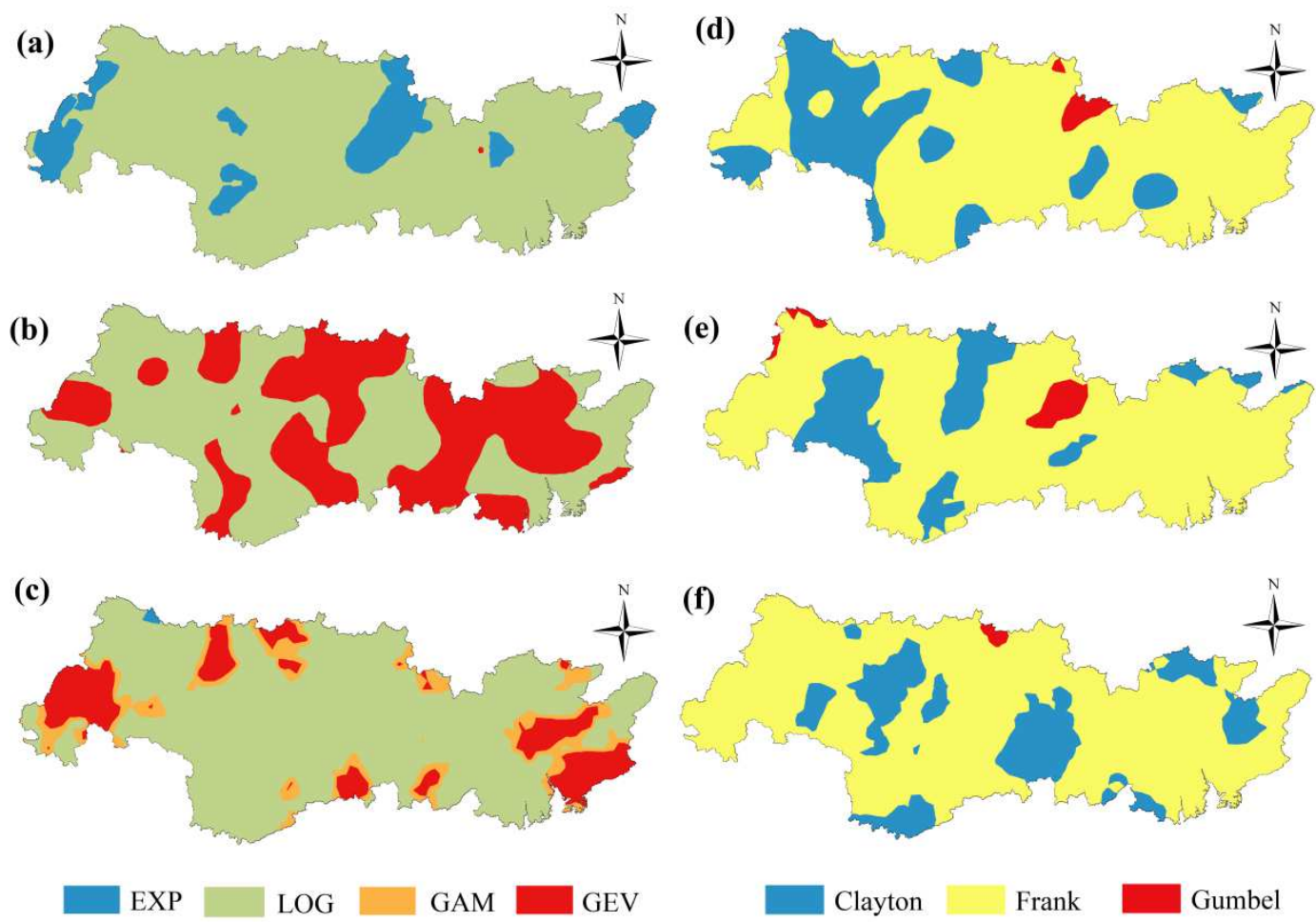

Fig. 4 Spatial distributions of the best-fitted marginal distribution functions of (a) $D$, (b) $I$, and (c) $P$ as well as the best-fitted copula functions of (d) $D-I$, (e) $D-P$, and (f) $P$ I over the PRB 

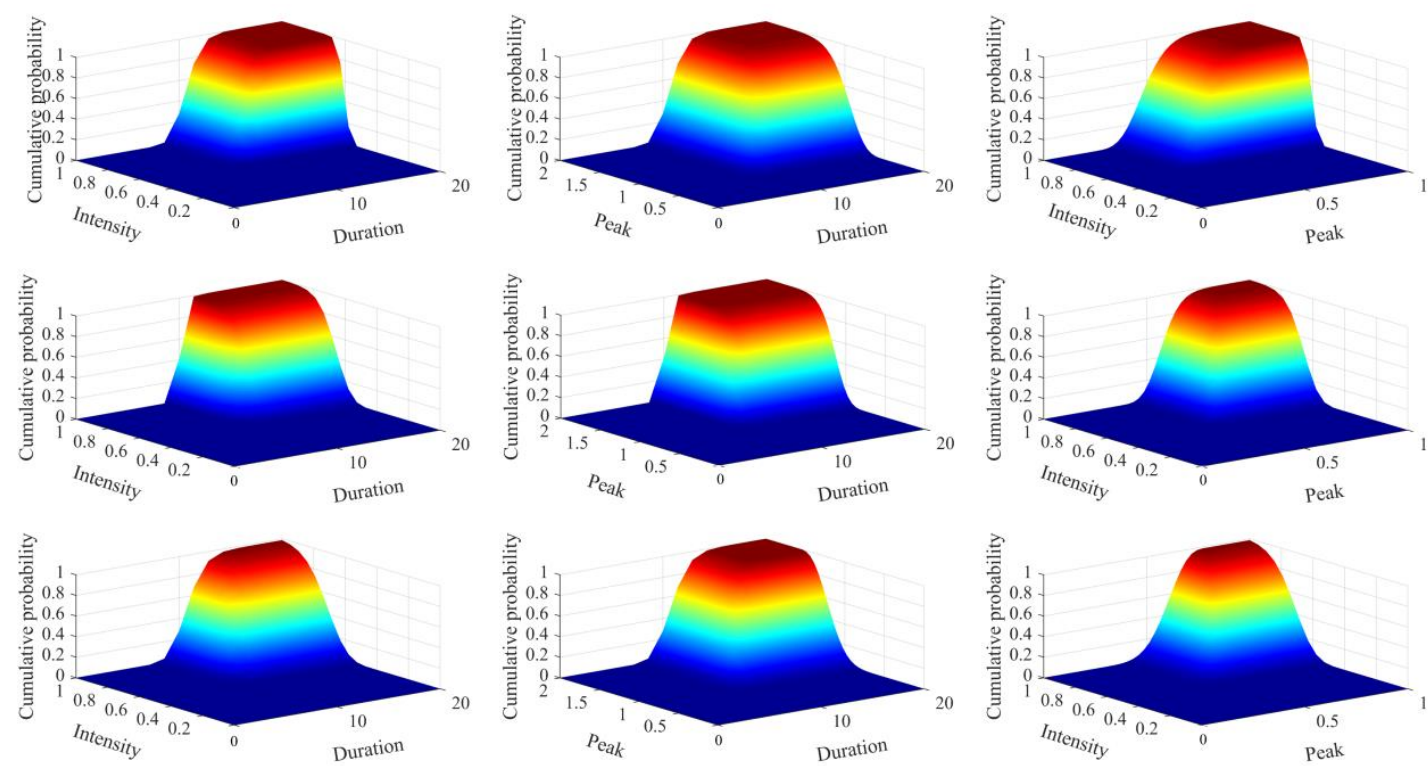

Fig. 5 Two-dimensional joint distribution maps of $D-I, D-P$, and $P-I$ in WRB (the first row), NRB (the second row), and ERB (the third row) 

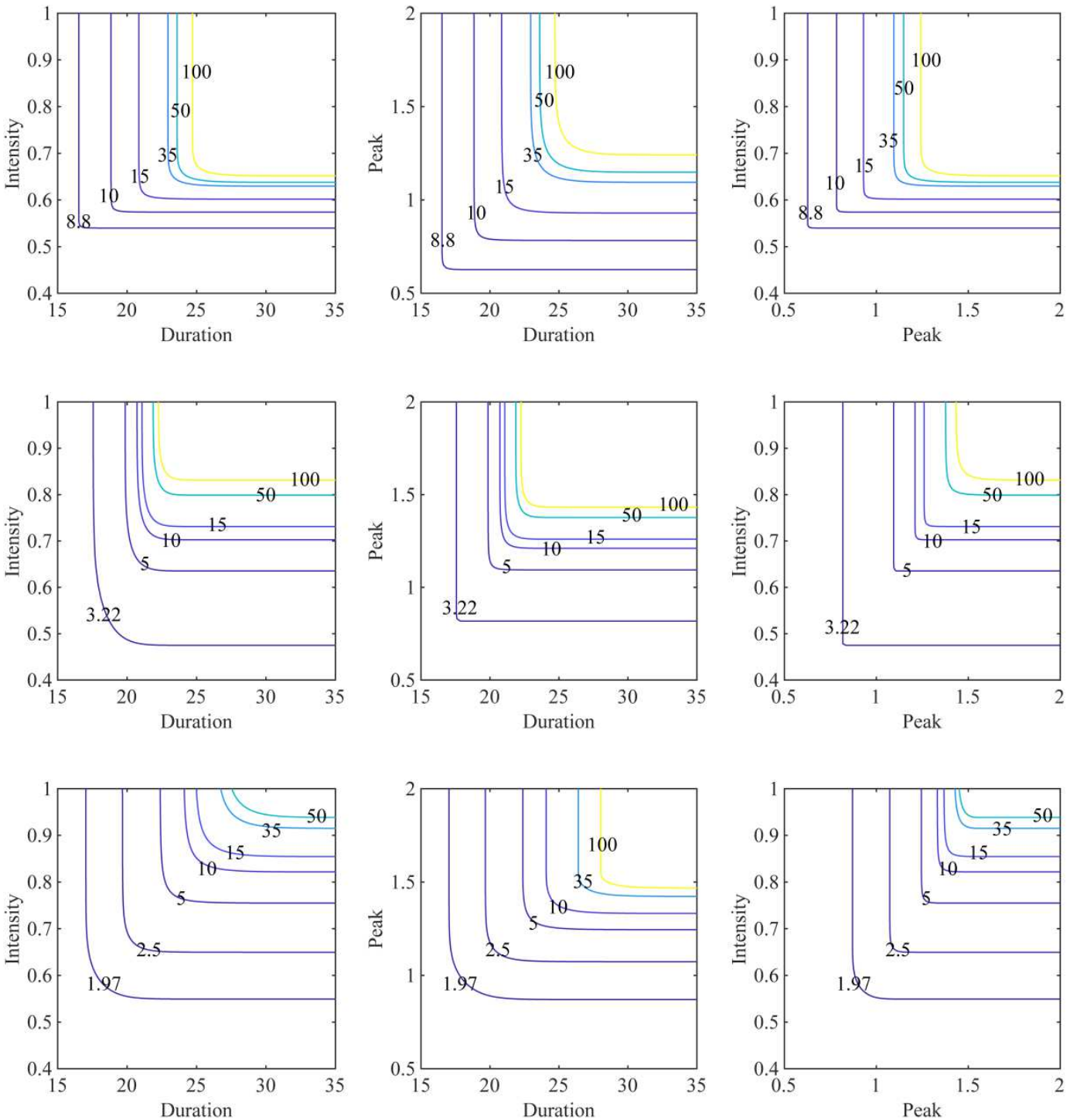

Fig. 6 The contour maps of the joint return period ( $T_{o}$ ) (in years) of $D-I, D-P$, and $P-I$ in WRB (the first row), NRB (the second row), and ERB (the third row) 

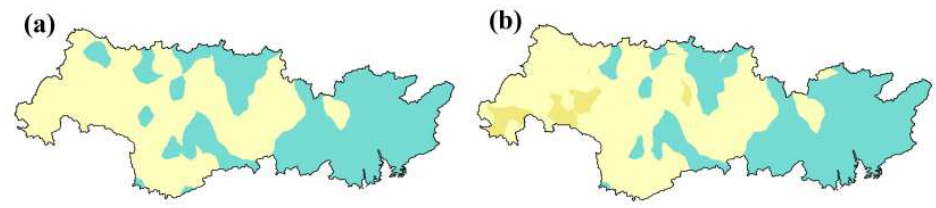

(c)
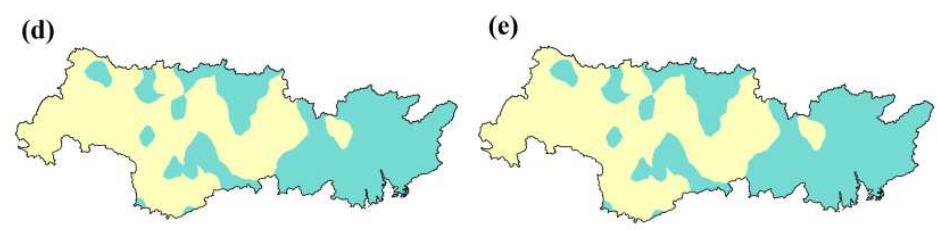

(f)
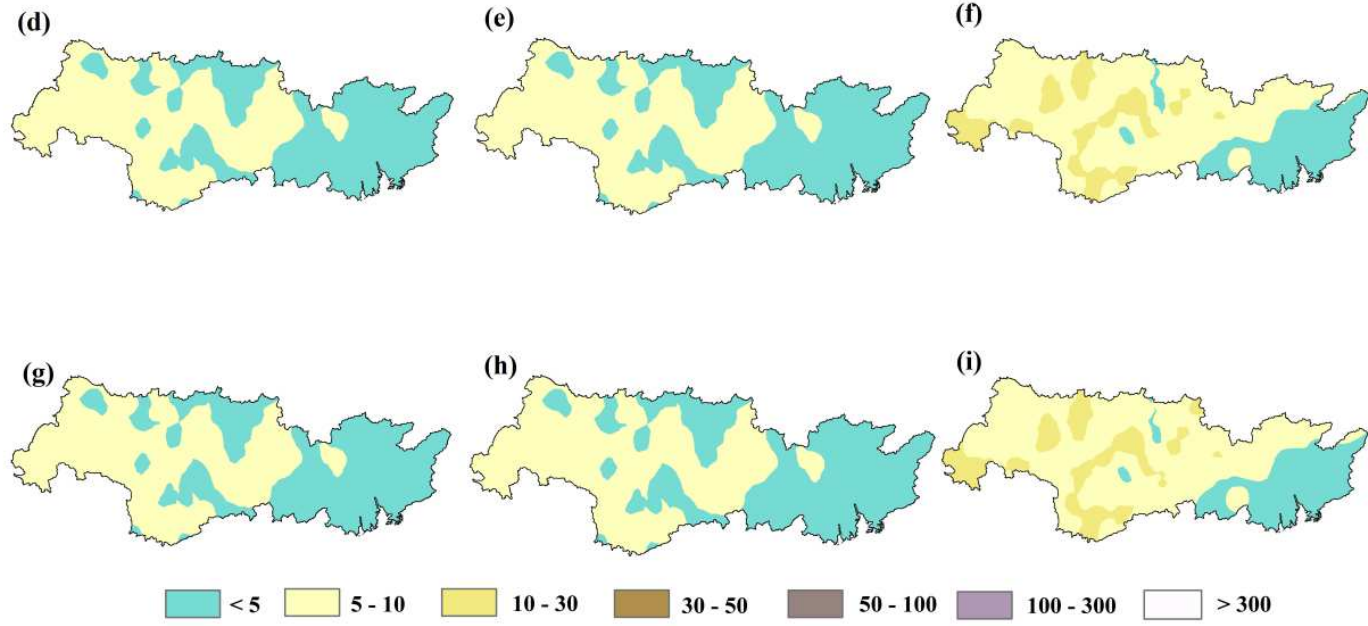

(h)

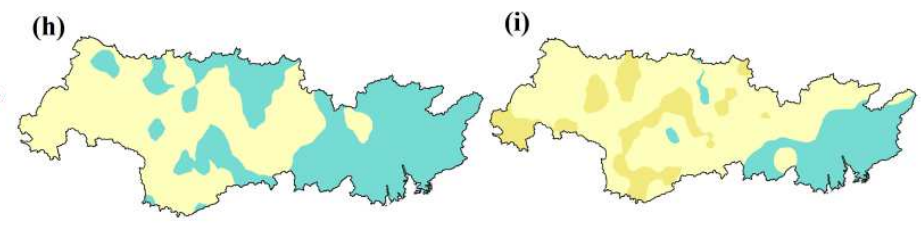

Fig. 7 Spatial distributions of $T_{o}$ (in years) of (a) $D 1-I 1$, (b) $D 2-I 2$, (c) $D 3-I 3$, (d) $D 1-$ $P 1$, (e) $D 2-P 2$, (f) $D 3-P 3$, (g) $I 1-P 1$, (h) $I 2-P 2$, and (i) $I 3-P 3$ over the PRB 

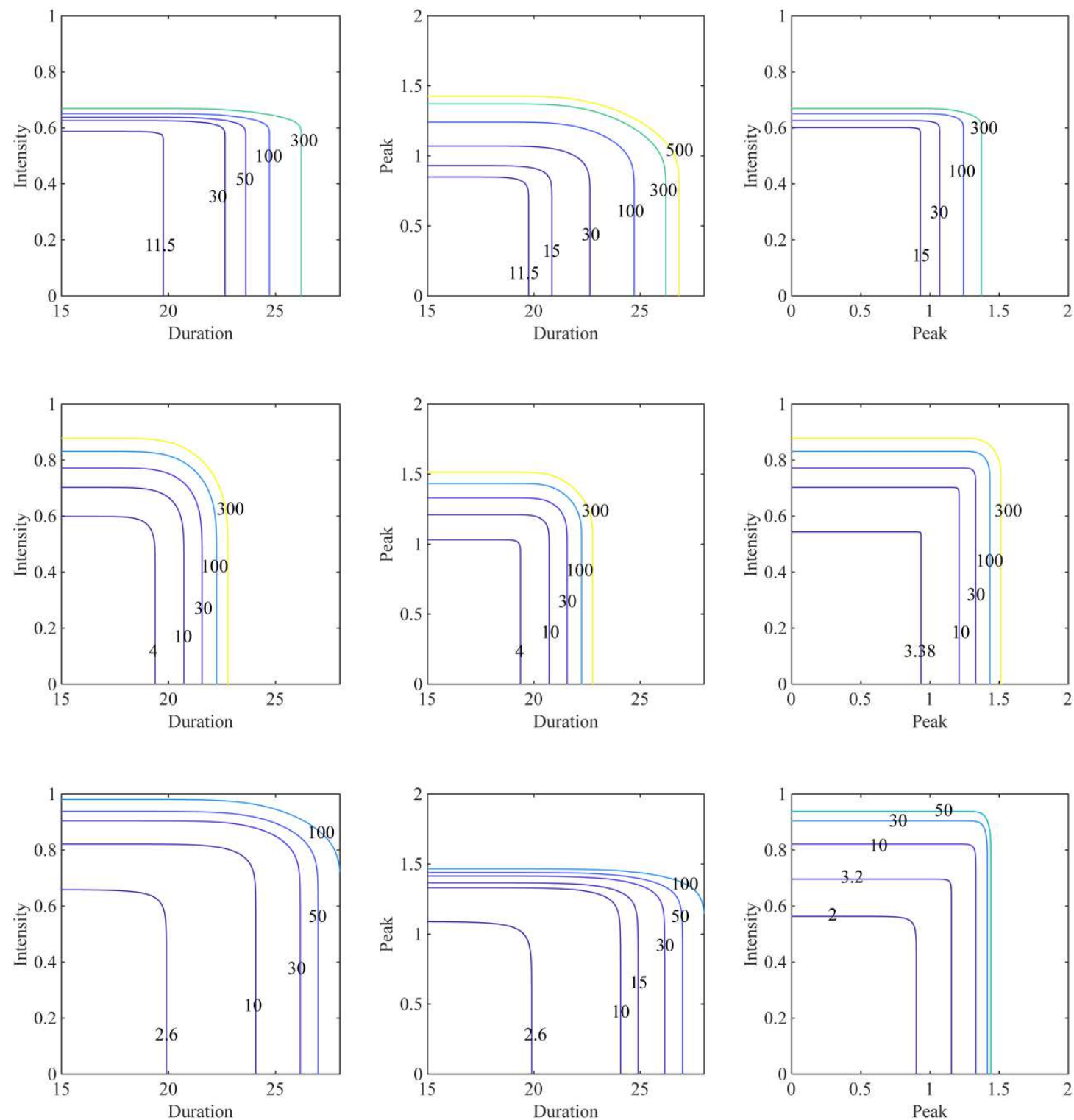

Fig. 8 The contour maps of the joint return period ( $\left.T_{a}\right)$ (in years) of $D-I, D-P$, and $P-I$ in WRB (the first row), NRB (the second row), and ERB (the third row) 

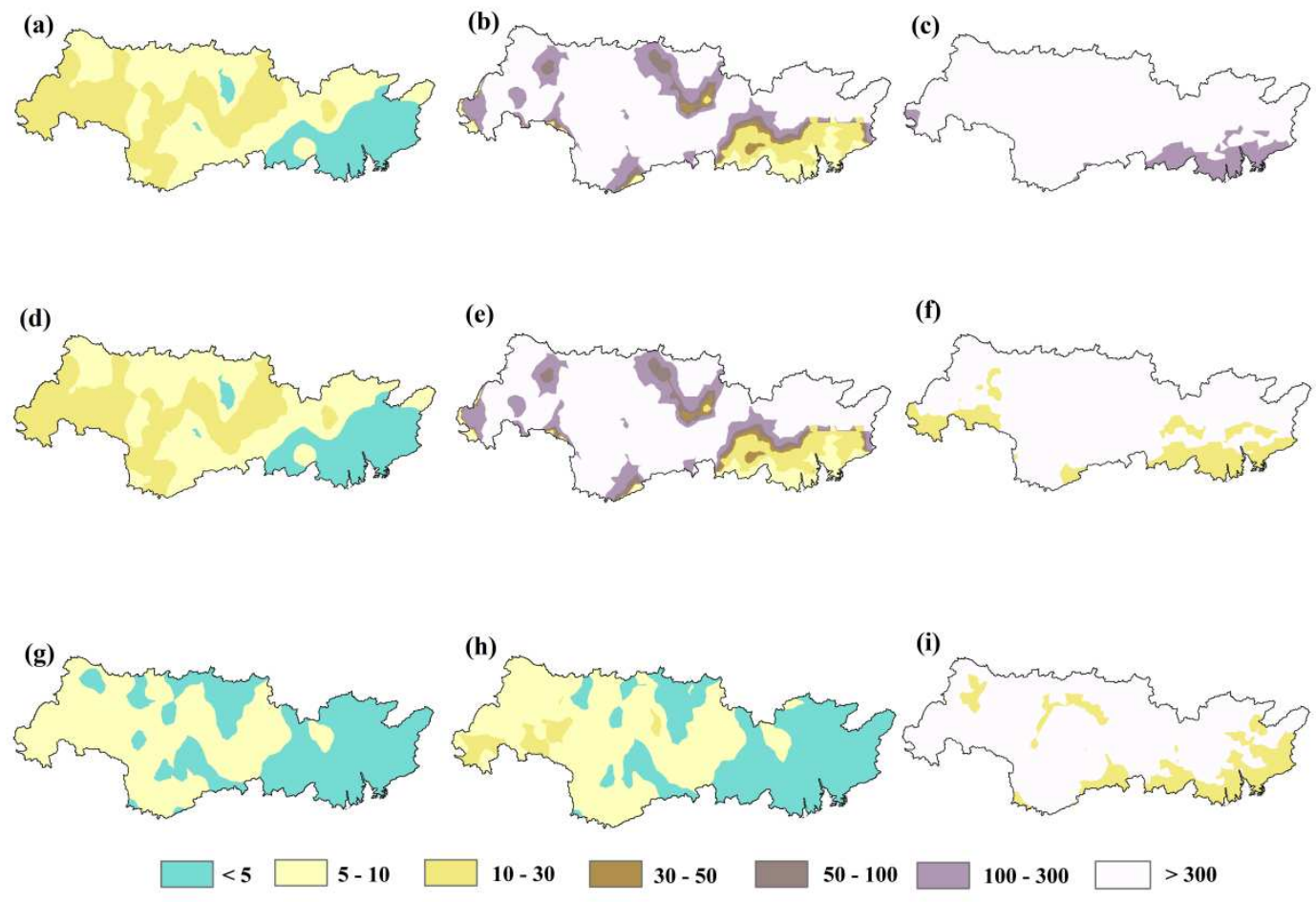

$\square$ 10 - 30 $\square 30-50$

$50-100$

$100-300$

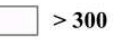

Fig. 9 Spatial distributions of $T_{a}$ (in years) of (a) D1-I1, (b) D2-I2, (c) D3-I3, (d) D1$P 1$, (e) $D 2-P 2$, (f) $D 3-P 3$, (g) II-P1, (h) I2-P2, (i) I3-P3 over the PRB. 